\title{
Glutamate Receptor-Dependent Modulation of Dopamine Efflux in the Nucleus Accumbens by Basolateral, But Not Central, Nucleus of the Amygdala in Rats
}

\author{
John G. Howland, ${ }^{1}$ Pornnarin Taepavarapruk, ${ }^{2}$ and Anthony G. Phillips ${ }^{1,2}$ \\ Departments of ${ }^{1} P$ sychology and ${ }^{2}$ Psychiatry, Brain Research Center, University of British Columbia, Vancouver, \\ V6T 2 A1 Canada
}

Dopaminergic neurotransmission in the nucleus accumbens (NAc) and neural processes in the basolateral (BLA) and central (CeN) amygdala nuclei are implicated in associative reward learning. Given their direct and indirect connections with the NAc and ventral tegmental area (VTA), both the BLA and CeN may regulate the mesoaccumbens dopamine (DA) system in rewarding situations. Electrical stimulation of the BLA $(20 \mathrm{~Hz}$, $10 \mathrm{sec}, 300 \mu \mathrm{A}$ ) induced a long-lasting $25 \pm 4 \%$ increase in DA efflux in the NAc, measured by microdialysis in freely moving rats, whereas comparable stimulation of the $\mathrm{CeN}$ had no effect. Reverse dialysis of either the NMDA receptor antagonist APV $(100 \mu \mathrm{M})$ or the AMPA-kainate receptor antagonist DNQX (100 $\mu \mathrm{M})$, but not the metabotropic glutamate receptor antagonist (土)-amino-4-carboxy-methyl-phenylacetic acid (100 $\mu \mathrm{M})$, into

The nucleus accumbens (NAc) plays a critical role in the acquisition and expression of appropriate behavioral responses to rewarding stimuli (Everitt et al., 1999, 2000; Ikemoto and Panksepp, 1999; Parkinson et al., 2000a). Reward-related information may be relayed to the NAc via glutamatergic inputs from the amygdala, hippocampus, and medial prefrontal cortex (Groenewegen et al., 1991; Brog et al., 1993; Meredith and Totterdell, 1999). Additionally, the NAc receives a dense dopaminergic projection originating in the ventral tegmental area (VTA) of the midbrain (Björklund and Lindvall, 1984). A growing body of evidence indicates that mesoaccumbens dopamine (DA) is an important neural modulator of both NAc medium spiny neurons (Harvey and Lacey, 1997; Hernándéz-López et al., 1997; Nicola et al., 2000) and their corticolimbic inputs (Wickens et al., 1996; Floresco et al., 2001a,b). Thus, DA neurotransmission may bias responses of the NAc to particular inputs that in turn may facilitate appropriate behavioral response selection in complex, rewarding situations (Mogenson et al., 1993; Ikemoto and Panksepp, 1999; Redgrave et al., 1999; Floresco et al., 2001a,b).

On the basis of behavioral and neurochemical experiments, the amygdala appears to regulate NAc DA efflux in rewarding envi-

Received Sept. 28, 2001; revised Nov. 9, 2001; accepted Nov. 14, 2001.

This work was supported by a grant from the Canadian Institutes of Health Research to A.G.P. J.G.H. is the recipient of a Natural Sciences and Engineering Research Council of Canada postgraduate scholarship. P.T. is a recipient of a Graduate Fellowship from the Royal Thai Government. We thank Dr. S. Ahn for helpful comments on this manuscript and K. So, C. Cheng, and L. GreggoriosPippas for technical support. We are eternally indebted to Dr. Stan B. Floresco for help with statistical analyses of these data.

Correspondence should be addressed to Dr. A. G. Phillips, Department of Psychiatry, University of British Columbia, 2255 Wesbrook Mall, Vancouver, British Columbia, Canada, V6T 2A1. E-mail: aphillips@cortex.psych.ubc.ca.

Copyright (C) 2002 Society for Neuroscience 0270-6474/02/221137-09\$15.00/0 the NAc blocked the stimulation-evoked increase in DA efflux in the NAc. VTA infusion of lidocaine (lido; 4\%) significantly reduced basal DA levels for $\sim 30$ min but failed to suppress the increase in NAc DA efflux resulting from BLA stimulation. Additionally, infusions of lido (4\%) into the medial prefrontal cortex failed to block the stimulation-evoked increase in NAc DA efflux. These data support the hypothesis that the BLA can directly modulate DA efflux through local mechanisms in the NAc, independent of an action on DA cell bodies in the VTA. The finding that brief activation of the $\mathrm{CeN}$ had no long-lasting effects on DA efflux in the NAc suggests an important degree of functional independence between the CeN and BLA.

Key words: basolateral amygdala; central amygdala; dopamine; nucleus accumbens; glutamate; reward ronments (Cador et al., 1989; Robledo et al., 1996; Floresco et al., 1998, 2001b; Everitt et al., 1999, 2000). The basolateral amygdala (BLA) sends a dense glutamatergic projection to the NAc (Kelley et al., 1982; Brog et al., 1993; Wright et al., 1996) that synapses in close apposition to mesoaccumbens DA varicosities (Johnson et al., 1994). The BLA and NAc interact during the formation and expression of stimulus-reward associations (Everitt et al., 1991; Robbins and Everitt, 1992; Baldwin et al., 2000), and afferent activity from the BLA can increase DA efflux via glutamatergic NMDA receptors in the NAc, which facilitates subsequent input from the BLA (Floresco et al., 2001b). The BLA may also regulate NAc DA efflux indirectly by altering DA cell body firing in the VTA via glutamatergic afferents to the medial prefrontal cortex (mPFC), which in turn projects to the VTA (Kelley et al., 1982; Jackson and Moghaddam, 2001).

The central nucleus of the amygdala $(\mathrm{CeN})$ is often considered to be the main output nucleus of the amygdala, primarily on the basis of its GABAergic efferents to midbrain autonomic sites (Kretteck and Price, 1978; Swanson and Petrovich, 1998). The CeN plays a critical role in both aversive and appetitive Pavlovian conditioning paradigms (Davis, 1992; Hatfield et al., 1996; Killcross et al., 1997; Parkinson et al., 2000b). Additionally, CeN lesions disrupt the potentiation of conditioned reinforcement by intra-accumbens amphetamine infusions (Robledo et al., 1996), which is dependent on mesoaccumbens DA transmission (Taylor and Robbins, 1986). The CeN may interact with the mesoaccumbens DA system through a direct GABAergic projection to the VTA (Wallace et al., 1992; Everitt et al., 1999, 2000), although other indirect routes are possible (Zahm, 2000). Taken together, these data suggest that the BLA and $\mathrm{CeN}$ may regulate mesoac- 
cumbens DA efflux differentially, thereby influencing the selection of appropriate response patterns to rewarding stimuli.

The present study used in vivo microdialysis in freely moving rats to examine the modulation of DA efflux in the NAc by brief stimulation of either the BLA or CeN. Given the findings of Floresco et al. (1998) in anesthetized rats and the data of Everitt and colleagues (Robledo et al., 1996; Everitt et al., 1999, 2000), we hypothesized that high-frequency electrical stimulation of either the BLA or CeN would increase DA efflux in the NAc. Stimulation parameters were based on single-unit recording studies demonstrating that amygdalar neurons fire at frequencies ranging from 10 to $40 \mathrm{~Hz}$ when rats are presented with either natural or conditional rewarding stimuli (Muramoto et al., 1993; Uwano et al., 1995; Pratt and Mizumori, 1998). Reverse dialysis of selective glutamate receptor antagonists into the NAc and microinfusions of lidocaine (lido) into either the VTA or mPFC were combined with BLA stimulation in separate experiments to examine the circuitry underlying the effects of stimulation on DA efflux in the NAc.

\section{MATERIALS AND METHODS}

Subjects. Male Long-Evans rats (Charles River Canada, St. Constant, Quebec, Canada) were used in all experiments. Rats were housed individually with ad libitum access to food (Purina Rat Chow) and water. All rats were maintained on a $12 \mathrm{hr}$ light/dark cycle (lights on at 7:00 A.M.). Experiments were conducted in strict accordance with the standards of the Canadian Council on Animal Care and were approved by the Committee on Animal Care at the University of British Columbia.

Surgery. Surgery was performed on rats weighing 320-400 gm. All rats were anesthetized with ketamine hydrochloride $(100 \mathrm{mg} / \mathrm{kg}$, i.p.; MTC Pharmaceuticals) and xylazine (10 mg/kg, i.p.; Rompun). They were then placed in a stereotaxic apparatus (Kopf, Tujunga, CA), the dorsal skull surface was exposed, and holes were drilled. A bipolar stimulating electrode with the tips spread to a diameter of $0.5 \mathrm{~mm}$ (Plastics One, Roanoke, VA) was implanted into either the BLA [anteroposterior (AP) $-3.4 \mathrm{~mm}$ from bregma, mediolateral (ML) $\pm 5.0 \mathrm{~mm}$ from the midline, dorsoventral (DV) $-7.6 \mathrm{~mm}$ from dura) or CeN (AP $-2.4 \mathrm{~mm}, \mathrm{ML} \pm 4.2$ $\mathrm{mm}, \mathrm{DV}-7.0 \mathrm{~mm})$, and a guide cannula (19 gauge, $15 \mathrm{~mm})$ was implanted dorsal to the ipsilateral NAc shell (AP $+1.8 \mathrm{~mm}, \mathrm{ML} \pm 1.1$ $\mathrm{mm}, \mathrm{DV}-1.0 \mathrm{~mm}$ ). Rats used in the VTA lidocaine (lido) experiment also had a guide cannula (23 gauge, $20 \mathrm{~mm}$ ) implanted dorsal to the ipsilateral VTA (AP $-4.8 \mathrm{~mm}, \mathrm{ML} \pm 1.0 \mathrm{~mm}, \mathrm{DV}-6.5 \mathrm{~mm}$ ), whereas rats used in the mPFC lido experiment had guide cannulas (23 gauge, 13 $\mathrm{mm}$ ) implanted dorsal to the mPFC bilaterally (AP $+3.4 \mathrm{~mm}, \mathrm{ML} \pm 0.7$ $\mathrm{mm}, \mathrm{DV}-2.5 \mathrm{~mm}$ ). All coordinates were calculated using the rat brain atlas of Paxinos and Watson (1997). Cannulas and the electrode were secured to the skull with four jeweler's screws and dental acrylic. Wire obdurators were inserted into the cannulas to keep them patent. Rats were given at least $5 \mathrm{~d}$ to recover from surgery before testing.

Microdialysis procedure. Concentric-style microdialysis probes $(2 \mathrm{~mm}$ of exposed membrane) were constructed in our laboratory (Taepavarapruk et al., 2000). Probes were attached to gas-tight syringes (Hamilton, Reno, NV) via a liquid swivel (Instech Inc., Plymouth Meeting, PA) containing perfusion medium $(147 \mathrm{~mm} \mathrm{NaCl}, 3.0 \mathrm{~mm} \mathrm{KCl}, 1.3 \mathrm{~mm}$ $\mathrm{CaCl}_{2} \cdot \mathrm{H}_{2} \mathrm{O}, 1.0 \mathrm{mM} \mathrm{MgCl} \mathrm{Mg}_{2} 0 \mathrm{H}_{2} 0$, and 0.01 sodium phosphate buffer, $\mathrm{pH}$ 7.3-7.4) and flushed for 10-20 min using a syringe pump (model 22; Harvard Apparatus, South Natick, MA). Probes were then secured in a copper collar and inserted into the NAc ( $7.8 \mathrm{~mm}$ ventral to dura), and the rats were allowed to move freely in a Plexiglas box $(32 \mathrm{~cm} \times 32 \mathrm{~cm} \times 41$ $\mathrm{cm}$ high) with access to food and water for $12-18 \mathrm{hr}$ before experimental testing began the following morning. The probes were continuously perfused at $1 \mu \mathrm{l} / \mathrm{min}$ overnight.

Analysis of dialysate samples. Two HPLC systems with electrochemical detection (HPLC-ED) consisting of an ESA 582 pump (ESA Inc., Bedford, MA), Rheodyne (Rohnert Park, CA) Inert manual injector, an Ultrasphere column (Beckmann, Fullerton, CA) (ODS $5 \mu \mathrm{m}, 15 \mathrm{~cm} \times$ $4.6 \mathrm{~mm})$, an ESA 5011 analytical cell, and a Coulochem II EC detector (ESA Inc.) were used to quantify DA levels in all experiments. The working potentials were: $+450 \mathrm{mV}$ (electrode 1$),-300 \mathrm{mV}$ (electrode 2$)$, and $+450 \mathrm{mV}$ (guard cell). The mobile phase ( $\mathrm{pH} 3.5$ ) consisted of 6 $\mathrm{gm} / 1$ sodium acetate, $10 \mathrm{mg} / 1$ EDTA, $150 \mathrm{mg} / 1$ octyl sulfate (adjustable),
$35 \mathrm{ml} / 1$ glacial acetic acid, and $865 \mathrm{ml}$ of Milli Q purified water. After it was filtered through a $0.22 \mu \mathrm{m}$ sterile nylon filter unit (Millipore, Bedford, MA), methanol (HPLC grade, $10 \%$ of total volume, adjustable) was added, and the mobile phase was degassed before use. Chromatograms were registered on a dual-pen chart recorder (Kipp and Zonen, Bohemia, NY). All samples were injected immediately after collection, and DA peak heights were measured manually.

Experimental procedure. A within-subjects design was used in all experiments, and this was combined with a between-subjects design for the VTA and mPFC lido experiments (see below). Samples were collected every $10 \mathrm{~min}$ throughout the experiment and after four baseline samples were collected that did not differ by more than $\pm 10 \%$, the rats received electrical stimulation. Cathodal constant current pulses were delivered to either the BLA or CeN through an isolator (Iso-flex; A.M.P.I., Jerusalem, Israel) via a Master-8 stimulator (A.M.P.I.). Two hundred pulses (0.4 msec duration) were delivered at an intensity of $300 \mu \mathrm{A}$ and a frequency of $20 \mathrm{~Hz}$ over $10 \mathrm{sec}$. The intensity of stimulation was based on a similar protocol used for stimulation of the ventral hippocampus in our laboratory (Taepavarapruk et al., 2000). Stimulation was timed to ensure that the next dialysis sample reflected only "stimulation-evoked" changes in DA efflux. The experimenter remained in the testing room after the stimulation to record any behavioral effects of the stimulation.

Pharmacological experiments in conjunction with BLA stimulation. In separate groups of rats, reverse dialysis was used to deliver the AMPAkainate receptor antagonist 6,7-dinitroquinoxaline-2,3-dione (DNQX), the NMDA receptor antagonist $( \pm)$-2-amino-5-phosphonopentanoic acid (APV), or the broad spectrum metabotropic glutamate receptor (mGluR) antagonist $(+)-\alpha$-methyl-4-carboxyphenylglycine (MCPG) to the NAc through the same probe used to collect samples. The dose of each drug in the perfusion medium was $100 \mu \mathrm{M}$. Previous experiments (Taepavarapruk et al., 2000) (P. Taepavarapruk and A. G. Phillips, unpublished observations) indicated that an intraprobe concentration of $100 \mu \mathrm{M}$ of each receptor antagonist is sufficient to block glutamatergic receptor activation effectively in the NAc. Perfusion of the drug into the NAc started 20 min before the second stimulation of the BLA and continued for a total of $60 \mathrm{~min}$.

Lidocaine microinfusion experiments in conjunction with BLA stimulation. Infusion needles were constructed from 30 gauge stainless steel tubing and PE-50 (Intramedic; Becton Dickinson, Mountain View, CA) tubing. The needles were filled with a $4 \%$ lido solution before being inserted into the VTA or mPFC. All needles were inserted $1 \mathrm{~mm}$ past the end of the cannulas into the VTA of mPFC at least $2 \mathrm{hr}$ before the experiment began. The microinfusion needles remained in place throughout the experiment.

Before the infusions, the needles were connected to gas-tight syringes (500 $\mu \mathrm{l}$; Hamilton, Reno, NV). The desired volume of lido (VTA: $2 \mu \mathrm{l}$, ipsilateral to the electrode; mPFC: $1 \mu \mathrm{l}$, bilateral) was infused $(0.5$ $\mu \mathrm{l} / \mathrm{min}$ ) via a syringe pump (model 22; Harvard Apparatus) $10 \mathrm{~min}$ before the second stimulation. The experimenter confirmed the progress of the infusion by measuring the movement of an air bubble in the PE-50 line during the infusion. Five minutes after the infusion ended, rats in the stimulation groups were stimulated a second time, whereas rats in the control groups were not (see Results). The effect of lido as a reversible $\mathrm{Na}^{+}$channel blocker is greatest $\sim 5$ min after infusion and may last for up to $30 \mathrm{~min}$ (Tehovnik and Sommer, 1997). Dialysate samples were collected for $60 \mathrm{~min}$ after the second stimulation in all experiments.

Drug preparation. Appropriate amounts of APV, DNQX, and MCPG (Precision Biochemical, Vancouver, Canada) were dissolved in a drop of $\mathrm{NaOH}$ and sterile $\mathrm{H}_{2} \mathrm{O}$ to create a $10 \mathrm{~mm}$ stock solution (volume was adjusted to $1 \mathrm{ml}$ with perfusion medium; $\mathrm{pH}$ was adjusted to $\sim 7.0$ ). The stock solutions were then diluted to $100 \mu \mathrm{M}$ with perfusion medium and stored at $-20^{\circ} \mathrm{C}$ until use. Lido $(4 \%)$ was made freshly before each experiment by dissolving $20 \mathrm{mg} / \mathrm{ml}$ of lido $\mathrm{HCl}$ powder (Research Biochemicals, Natick, MA) into an injectible 2\% lido solution (Ayerst, Guelph, Ontario, Canada).

Histology. After the experiments, all rats were injected with a lethal dose of chloral hydrate and perfused transcardially with $0.9 \%$ saline followed by $10 \%$ formaldehyde. Brains were stored in $10 \%$ sucrose in $10 \%$ formaldehyde for at least 1 week, after which they were sectioned $(50 \mu \mathrm{m})$ using a cryostat and stained for Nissl substance with cresyl violet. Placements of the probes, electrodes, and infusion needles were verified under a light microscope with the assistance of a rat brain atlas (Paxinos and Watson, 1997).

Data analysis. The height of each DA peak was measured directly from the chromatograms, and baseline DA levels for each rat were calculated 
by averaging the first three samples included in the analysis. In all figures, DA levels are expressed as a percentage of the baseline. One-way repeated measures ANOVAs with time as a within-subjects factor were performed with the aid of SPSS (version 10.0) on all data, and Dunnett's post hoc tests were performed where appropriate. The baseline sample taken immediately before the first stimulation was used as the critical value during computation of the Dunnett's post hoc tests. To assess differences between groups in the lido experiments, planned contrasts between samples for time points of interest were computed, and significance was determined using the Bonferroni correction for $\alpha$ levels.

\section{RESULTS}

\section{High-frequency stimulation of the BLA, but not the CeN, induces a long-lasting increase in NAc DA efflux}

As shown in Figure $1 A$, baseline DA levels were very stable before brain stimulation. High-frequency stimulation $(20 \mathrm{~Hz} ; 10$ sec; $300 \mu \mathrm{A} ; n=7)$ of the BLA induced a significant $\left(F_{(21,126)}=\right.$ 3.68; $p<0.0001$; Dunnett's, $p<0.05)$ increase in DA efflux in the NAc that returned to baseline $30 \mathrm{~min}$ after the stimulation (Fig. $1 A)$. A second train of brain stimulation $2 \mathrm{hr}$ (12 samples) after the first stimulation also produced a significant increase in DA efflux (Dunnett's, $p<0.05$ ). DA levels returned to baseline 40 min after stimulation, and the experiment was terminated $60 \mathrm{~min}$ after the second stimulation.

Throughout testing, rats generally slept and rested except for exhibiting a number of characteristic behavioral responses immediately after stimulation of the BLA. Behavioral responses to stimulation are summarized in Table 1. The only unexpected behavioral response to the stimulation was a characteristic rapid turn between $90^{\circ}$ and $270^{\circ}$ during the stimulation exhibited by $35 \%$ of the rats receiving BLA stimulation. In $87 \%$ of these rats, the turn was ipsilateral to the electrode. The behavioral responses exhibited by a given rat were similar after the first and second stimulation and during the pharmacological and lido experiments. Thus, it is likely these behavioral changes were caused by activation of the amygdala and were unrelated to the changes in DA efflux observed in the NAc.

Histological analyses from all experiments involving BLA stimulation confirmed that a significant stimulation-evoked increase in DA efflux in the NAc was observed only when electrode placements were located in the caudal BLA $(n=46)$ (Fig. 1C). The majority of effective placements (shown on the left side of the sections) were centered in the caudal magnocellular accessory basal and parvicellular basal nuclei $(-3.3 \mathrm{~mm},-3.6 \mathrm{~mm}$, and $-3.8 \mathrm{~mm}$ from bregma). The right side of each section depicts a representative sample of placements from rats which did not show an increase in DA efflux in the NAc when stimulated $(n=30)$. These placements were located in the lateral nucleus of the amygdala $(n=11)$, ventral piriform cortex $(n=8), \operatorname{CeN}(n=4)$, bed nucleus of the stria terminalis $(n=5)$, and caudate putamen $(n=2)$. Six rats represented by placements shown on the right side of this figure served as the stimulated control group (Stimctrl + lido) in the VTA-lido experiment discussed below. Representative placements of the microdialysis probes used in all experiments are shown in Figure $1 D$. Many of the probes were centered on the border between the shell and core of the NAc, and sampled primarily from areas where BLA afferents terminate.

In contrast to the data obtained with placements in the BLA, electrical stimulation of the $\mathrm{CeN}(20 \mathrm{~Hz} ; 10 \mathrm{sec} ; 300 \mu \mathrm{A} ; n=6)$ failed to produce a significant change in DA efflux in the NAc (data not shown; $F_{(9,45)}=1.32 ; \mathrm{NS}$ ). To ensure that this finding was not caused by insufficient current intensity, an additional group of eight animals were implanted with electrodes in the $\mathrm{CeN}$ and stimulated at intensities of 300, 450, 600, and $800 \mu \mathrm{A}$ with 60 min between each stimulation. Dialysis samples were collected continuously for the duration of this experiment, and no significant change in NAc DA efflux was detected at any of these current intensities (Fig. 1B) $\left(F_{(27,189)}=1.34\right.$; NS). It is interesting to note that after the $800 \mu \mathrm{A}$ stimulation (Fig. $1 B, S 4$ ), there was a small nonsignificant increase in DA efflux in the NAc. This effect may be attributable to the spread of the high current intensity that activated a portion of the BLA in some animals. Behavioral effects of $\mathrm{CeN}$ stimulation were similar to those observed after BLA stimulation and are also described in Table 1. Rats in the parametric study $(300-800 \mu \mathrm{A})$ displayed an increase in the duration of chewing behaviors at higher current intensities. Stimulating electrodes in the $\mathrm{CeN}$ group were located in the lateral and medial divisions of the $\mathrm{CeN}(n=14)$ (Fig. $1 D)$.

\section{Increased NAc DA efflux after stimulation of the BLA is dependent on ionotropic glutamate receptors located in the NAc}

Reverse dialysis experiments examined the role of both ionotropic and metabotropic glutamate receptors in the NAc in the effects of BLA stimulation on NAc DA efflux. Control stimulation of the BLA before delivery of the ionotropic glutamate receptor (iGluR) antagonists APV $(n=7)$ or DNQX $(n=8)$ resulted in a significant increase in DA efflux in the NAc similar to that observed above (Fig. 2) (APV group: $F_{(21,126)}=2.39, p<0.005$; Dunnett's, $p<0.05$; DNQX group: $F_{(21,147)}=4.44, p<0.0001$; Dunnett's, $p<0.05)$. Reverse dialysis of either APV $(100 \mu \mathrm{M})$ or DNQX $(100 \mu \mathrm{M})$ for $20 \mathrm{~min}$ before, and $40 \mathrm{~min}$ after, the second BLA stimulation blocked the increase in DA efflux (Fig. 2, Dunnett's, NS). In contrast, reverse dialysis of the mGluR antagonist MCPG $(100 \mu \mathrm{M})$ failed to block BLA stimulation-evoked increase in DA efflux $\left(n=6 ; F_{(21,105)}=2.05 ; p<0.01\right.$; Dunnett's, $p<0.05$ for both the first and second stimulation).

Application of these drugs did not change the behavior of the rats or significantly affect basal DA levels. However, as can been seen in Figure 2, reverse dialysis of DNQX into the NAc did cause a small, nonsignificant $(10 \pm 6 \%)$ decrease in basal DA levels in the NAc 10 min after administration began (immediately preceding stimulation 2). This effect has been seen previously (Taepavarapruk et al., 2000) and may reflect a role for AMPAkainate receptors located in the NAc in regulating basal levels of DA release.

\section{Infusion of lidocaine into the VTA significantly reduced basal DA levels in the NAc but failed to attenuate the BLA stimulation-evoked increase in NAc DA efflux}

The next experiment assessed the contribution of DA cell body firing in the VTA to the increase in NAc DA efflux after stimulation of the BLA. The general design was the same as the previous experiments except three groups of rats were used, including one group receiving lido alone. After baseline sampling, the group receiving BLA stimulation before lido treatment (BLAstim + lido group; $n=9)$ showed the characteristic, significant increase in NAc DA efflux (Fig. $3 A)\left(F_{(18,342)}=13.4 ; p<\right.$ 0.0001; Dunnett's test, $p<0.05$, BLAstim + lido group only; between groups contrast: $\left.t_{(19)}=2.73 ; p<0.01\right)$ as observed in the previous experiments. Brain stimulation at control sites (Stimctrl + lido; $n=6$ ) failed to evoke an increase in NAc DA efflux (Dunnett's test, $N S$ ). As shown in Figure $1 C$, stimulation of only the caudal BLA resulted in a significant increase in DA efflux in the NAc. Histological analysis revealed that the stimulating electrodes in the Stimctrl + lido group were positioned outside this 
A

BLA Stimulation

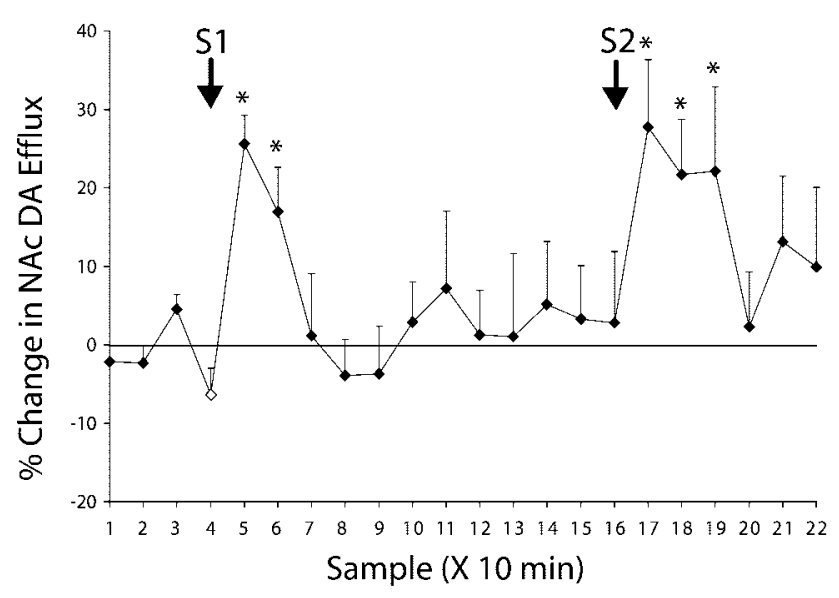

C

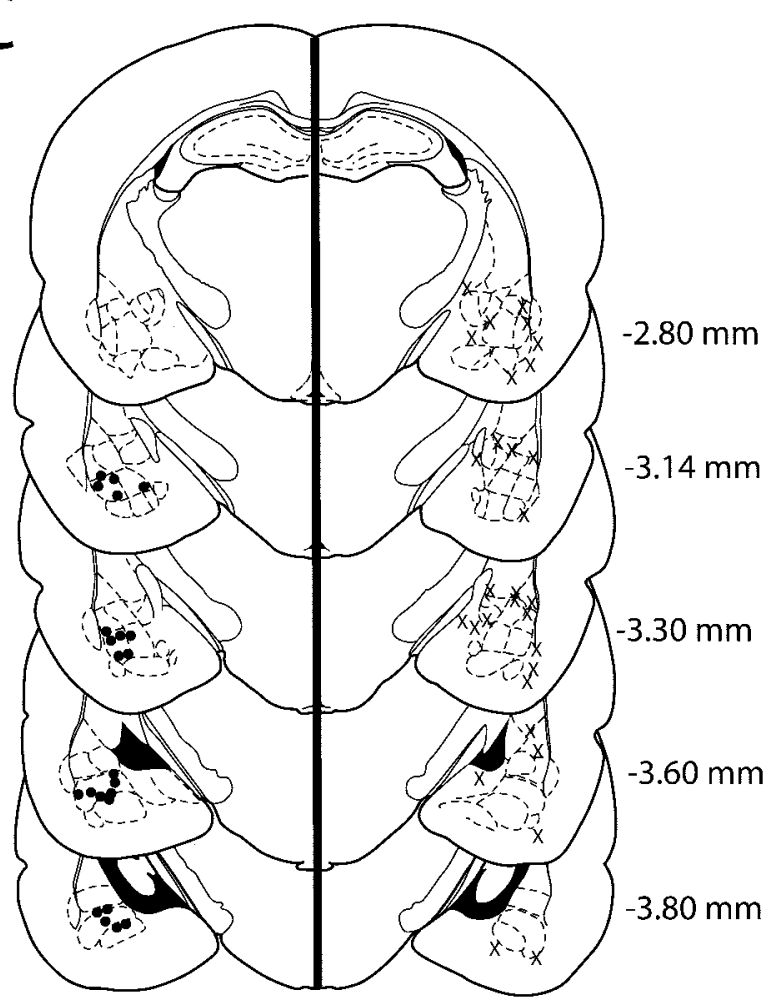

B CeN Stimulation

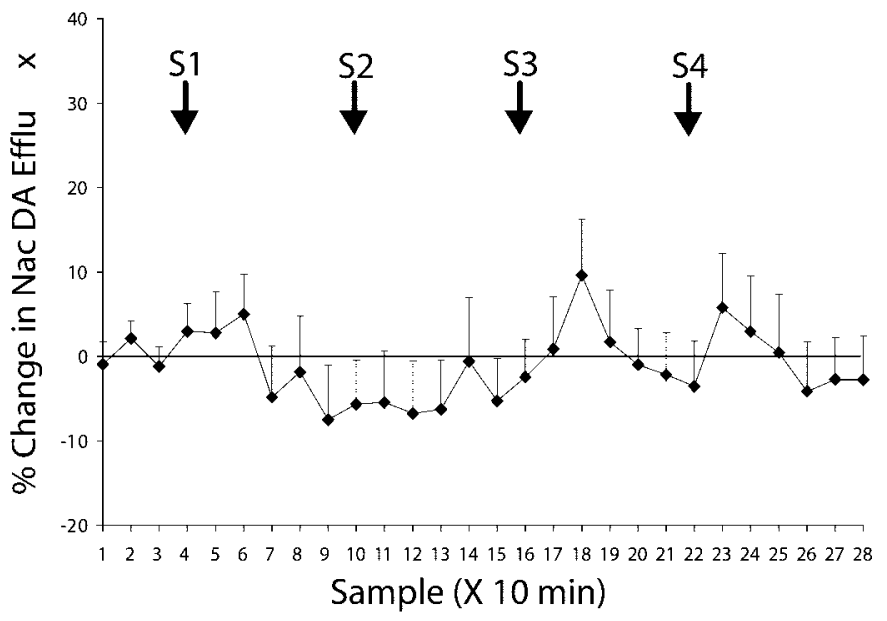

D

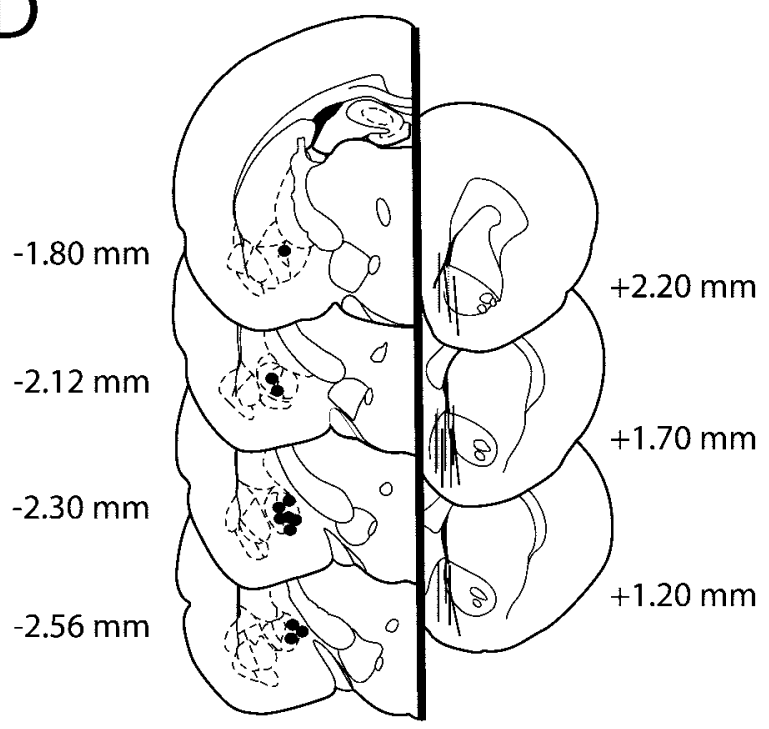

Figure 1. Effects of high-frequency stimulation of the BLA and CeN on DA efflux in the NAc. A, High-frequency stimulation of the BLA (20 Hz, 10 sec, $n=7, S 1)$ followed $2 \mathrm{hr}$ later by a second train of stimulation $(20 \mathrm{~Hz}, 10 \mathrm{sec}$, S2). Asterisks denote significant differences from baseline (white diamond) at the level of $p<0.05$. Data points represent a mean level of DA obtained over a 10 min sampling period (see Materials and Methods for details), and error bars represent SEM (for both $A$ and $B) . B$, High-frequency stimulation $(20 \mathrm{~Hz}, 10 \mathrm{sec})$ of the CeN at four different current intensities $(S 1=300 \mu \mathrm{A}, S 2=450 \mu \mathrm{A}, S 3=600 \mu \mathrm{A}, S 4=800 \mu \mathrm{A})$ failed to induce significant changes in DA efflux $(n=8)$. $C$, Representative placements of electrodes of effective (left side, black circles) and ineffective (right side, black " $x$ ") sites for inducing an increase in DA efflux, in all experiments. For clarity not all placements are shown. Numbers correspond to the anterior or posterior distance (in millimeters) of each plate from bregma (both $C$ and $D)$. D, Representative placements of electrodes aimed at the CeN (left side, black circles) and microdialysis probes aimed at the NAc (right side). The black bars illustrate the position of the probes and are scaled to $2 \mathrm{~mm}$ in length to accurately reflect only the area of the brain from which each probe sampled. Plates adapted from Paxinos and Watson (1997).

area; therefore, this group provided a control for the generalized effects of stimulating areas surrounding the BLA on NAc DA efflux in conjunction with the VTA lido infusion.
Microinf usion of lido into the VTA $(2 \mu \mathrm{l}, 0.5 \mu \mathrm{l} / \mathrm{min}$, ipsilateral to the electrode) significantly reduced basal DA levels in all three groups $\left(F_{(18,342)}=13.4 ; p<0.0001\right.$; Dunnett's, $p<0.05$, all 


\begin{tabular}{lcc}
\hline Table 1. Behavioral responses of rats to stimulation of the BLA or CeN \\
& $\begin{array}{c}\text { BLA }(n=46) \\
(\%)\end{array}$ & $\mathrm{CeN}(n=14)$ \\
Behaviors & 100 & 100 \\
\hline Awaken & 82 & 64 \\
Mouth movements/chewing & 35 & 21 \\
Rapid turn during stimulation & & \\
Return to sleeping/resting & 25 & 36 \\
$\quad(<2$ min $)$ & 64 & 43 \\
$\quad(>2$ min, $<5$ min $)$ & 11 & 21 \\
$\quad(>5$ min $)$ & 16 & 0 \\
Wet dog shake & &
\end{tabular}

Number of rats displaying a particular behavior is expressed as a percentage of the total number of rats receiving stimulation.

groups) consistent with a blockade of $\mathrm{Na}^{+}$channels by lido that in turn reduced firing of DA neurons in the VTA. As can be seen from Figure $3 A$, DA efflux in the three groups was reduced by $35-40 \%, 10$ min after inf usion of lido. DA levels in the lido group remained significantly below baseline for the next 20 min (Dunnett's, $p<0.05)$ reaching a nadir of $54 \pm 4 \%$ below baseline 20 min after the infusion of lido was terminated. As expected, stimulation at control sites in the Stimctrl + lido group after the lido infusion did not change DA levels relative to the lido group, and levels of DA efflux remained significantly below baseline values for a total of $30 \mathrm{~min}$ (Dunnett's, $p<0.05$ ). The $30 \mathrm{~min}$ duration of this effect reflects the typical time course of lido in brain tissue (Tehovnik and Sommer, 1997) and confirms the success of the infusions.

In contrast to the data from the two control groups, brain stimulation in the BLAstim + lido group significantly increased NAc DA efflux relative to the attenuated baseline $10 \mathrm{~min}$ after the lido infusion (Dunnett's, $p<0.05$ ). DA efflux in the BLAstim + lido group was $42 \%$ higher than the two control groups (Fig. $3 B$ ), however, values were not increased above baseline. DA efflux in the BLAstim + lido group remained significantly higher than control values for at least $10 \min \left(t_{(19)}=8.94 ; p<0.0005\right)$, after which the control values returned to baseline levels. Placements of the microinfusion cannulas aimed at the VTA in this experiment are shown in Figure $3 C$.

\section{Bilateral infusions of lidocaine into the MPFC fail to affect the BLA stimulation-evoked increase in NAC DA}

Using a design similar to that of the VTA lido experiment described above, the final experiment assessed the possible contribution of the glutamatergic projection from the BLA to the mPFC in modulating the effects of BLA stimulation on NAc DA efflux. As is shown in Figure 4, initial stimulation of the BLA (BLAstim + lido group; $n=9$ ) induced a significant $23 \pm 5 \%$ increase in NAc DA efflux $\left(F_{(18,288)}=2.06, p<0.01\right.$, Dunnett's, $p<0.05$; between groups contrast: $\left.t_{(16)}=4.17, p<0.0005\right)$ that remained significantly above baseline levels for $60 \mathrm{~min}$. Bilateral infusion of lido ( $1 \mu \mathrm{l} / \mathrm{side})$ into the $\mathrm{mPFC}$ was accompanied by a small reduction in basal DA release in the control group (lido group; $n=9$ ) for 10 min after infusion (Fig. 4).

Infusion of lido bilaterally into the mPFC failed to block the BLA stimulation-evoked increase in NAc DA efflux (Dunnett's, $p<0.05$; between groups contrast: $\left.t_{(16)}=2.70, p<0.01\right)$, suggesting that the BLA afferents to the mPFC do not contribute significantly to the increases in NAc DA efflux after BLA stimulation. The infusion cannulas of the rats used in this experiment were positioned within the infralimbic and prelimbic areas of the mPFC (Fig. 3C).

\section{DISCUSSION}

Brief, high-frequency stimulation of the BLA caused a longlasting increase in DA efflux in the NAc of awake, unrestrained rats. Both the magnitude and duration of this increase is similar to that observed in the NAc of rats presented with natural rewards such as food (Ahn and Phillips, 1999). In contrast, stimulation of the $\mathrm{CeN}$ at similar and higher current intensities did not produce significant changes in DA efflux. After stimulation of either nucleus, the animals displayed increased levels of activity and alertness for a number of minutes. Reverse dialysis of the iGluR antagonists APV and DNQX, but not the mGluR antagonist MCPG, into the NAc blocked the BLA stimulation-evoked increase in NAc DA efflux. Histology results, summarized in Figure $1 C$, indicate that stimulation of only the caudal BLA resulted in increased NAc DA efflux, consistent with the location of a direct glutamatergic projection to the NAc (Kelley et al., 1982; Brog et al., 1993; Wright et al., 1996). Inactivation, with the $\mathrm{Na}^{+}$channel blocker lido, of either the mesoaccumbens DA cell bodies in the VTA, or the region of the $\mathrm{mPFC}$ that receives a glutamatergic projection from the BLA, failed to block the BLA stimulation-evoked increase in DA efflux in the NAc. These results complement data from the anesthetized preparation (Floresco et al., 1998) and suggest that the BLA may modulate NAc DA efflux via a local mechanism in the NAc.

\section{Distinct patterns of NAc DA modulation by the BLA and $\mathrm{CeN}$}

The BLA and CeN interact with the mesoaccumbens DA system via different pathways, and this may partially account for the different effects on NAc DA efflux observed after stimulation of these amygdalar nuclei. For example, the BLA sends a direct

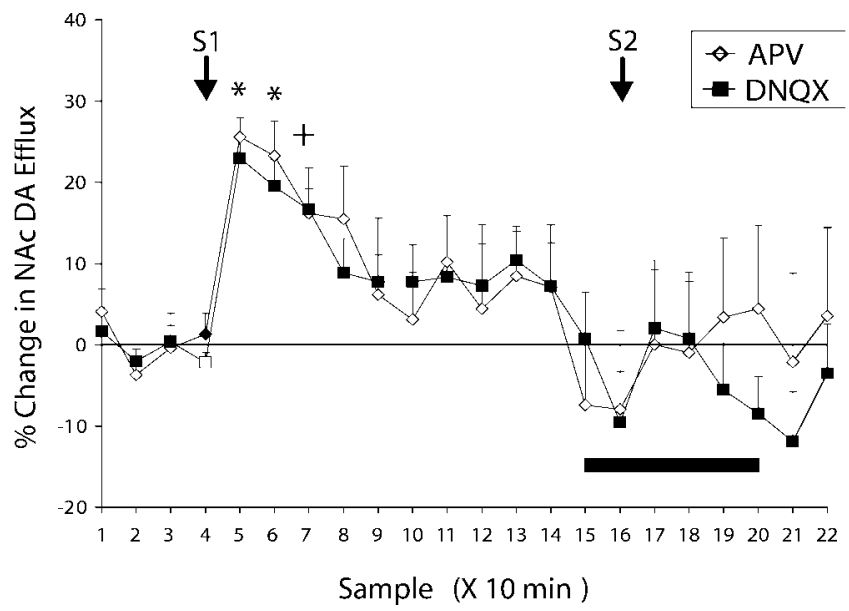

Figure 2. Reverse dialysis of ionotropic glutamate receptor antagonists into the NAc and the effect of BLA stimulation on NAc DA efflux Stimulation of the BLA $(20 \mathrm{~Hz}, 10 \mathrm{sec}, S 1)$ induced a significant increase in DA efflux in the NAc in both groups $(p<0.05)$. Reverse dialysis of either the NMDA receptor antagonist APV (100 $\mu \mathrm{M}, n=7$; white diamonds $)$ or the AMPA-kainate receptor antagonist DNQX $(100 \mu \mathrm{M}$, $n=8$; black squares) blocked the expected increase in DA efflux after the second (S2) stimulation of the BLA $(20 \mathrm{~Hz}, 10 \mathrm{sec})$. Asterisks denote a significant difference from baseline (APV, black diamond; DNQX, white square) for both groups $(p<0.05)$, whereas the cross denotes a significant difference from baseline for only the DNQX group. Error bars represent SEM, and the horizontal bar represents the time period during which APV or DNQX was administered into the NAc by reverse dialysis. 

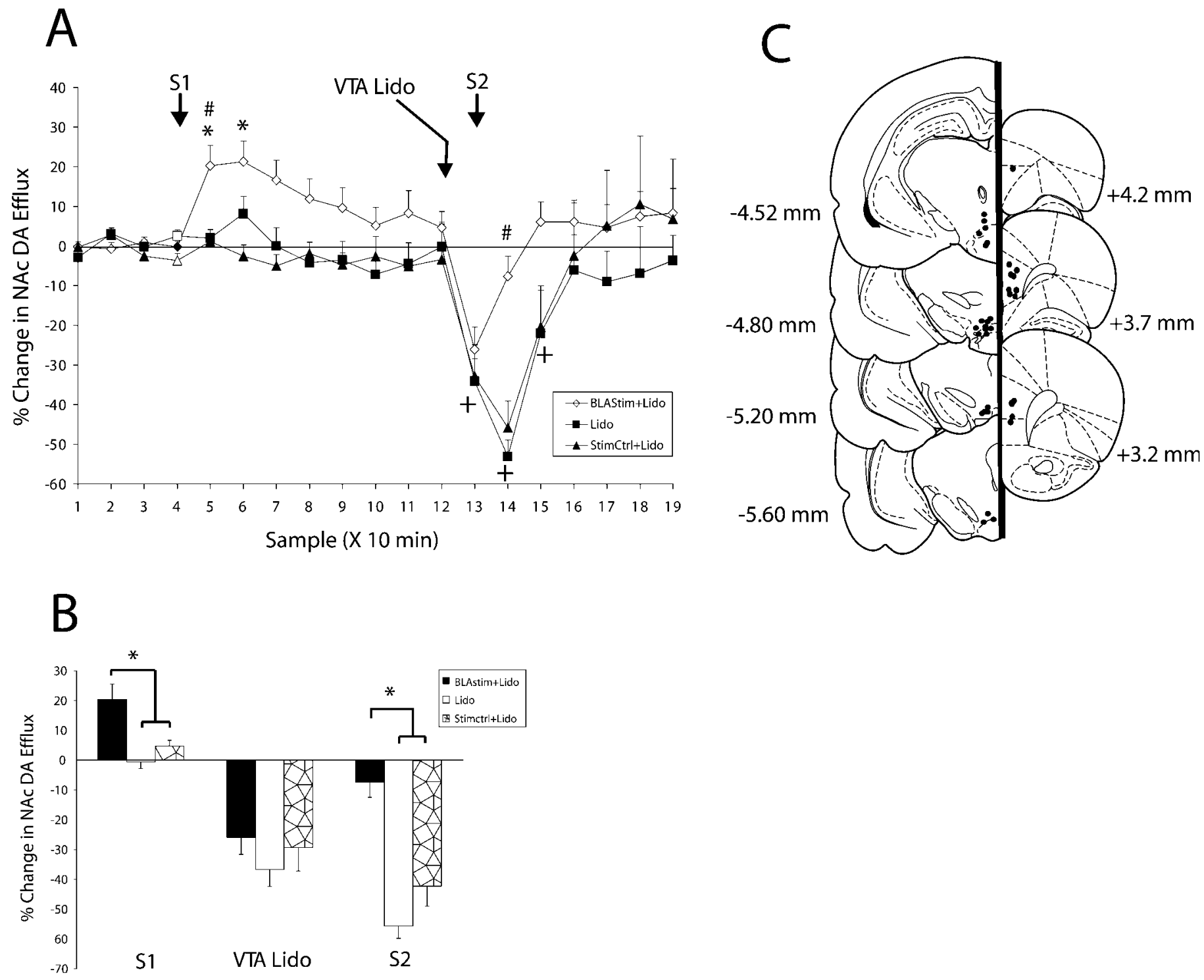

Figure 3. Effect of VTA lido infusion on NAc DA efflux evoked by stimulation of the BLA. A, Stimulation of the BLA (20 Hz, 10 sec, S1) induced a significant increase in DA efflux $(20 \pm 5 \%)$ in the NAc of the BLAstim + lido group (white diamonds; $n=9)$ but not in the Stimctrl + lido $($ black triangles; $n=6)$ group. Histological analyses revealed that the electrodes of the Stimctrl + lido group were located outside the caudal BLA (see Results). lido inf usion into the VTA of all groups $(2 \mu \mathrm{l}$, unilateral, VTA lido $)$, caused a significant decrease in basal DA levels in all groups. 10 min after lido inf usions, the BLAstim + lido and Stimctrl + lido groups were stimulated a second time (20 Hz, $10 \mathrm{sec}, S 2)$. After stimulation, DA levels in the NAc of the Stimctrl + lido group were reduced further and were comparable with values of the lido group. DA levels in the BLAstim + lido group were significantly higher than those of the lido and Stimctrl + lido groups for $10 \mathrm{~min}$ after the second stimulation (these data are summarized in $B$ ). Error bars represent SEM. Asterisks denote a significant increase in DA levels above baseline (BLAstim + lido group, black diamond; lido and Stimctrl + lido groups, white square and white triangle, respectively; $p<0.05)$. Crosses indicate a significant decrease in DA levels from baseline $(p<0.05)$. Number signs indicate a significant difference between groups $(p<0.001)$. B, Summary of DA levels for the BLAstim + lido (black bars), lido (white bars), and Stimctrl + lido (hatched bars) groups after the first stimulation (S1), VTA lido infusion (VTA-lido), and the first sample taken after the second stimulation (S2). See $A$ for details. Asterisks denote a significant difference between groups $(p<0.001)$. C, Placements of the microinf usion needles aimed at the VTA (left side $)$ and mPFC (right side) in the lido experiments. See Figure $1 C$ for additional details.

glutamatergic projection to the NAc (Kelley et al., 1982; Brog et al., 1993; Wright et al., 1996) which, given the results of the present experiments, could modulate NAc DA efflux after BLA stimulation. Furthermore, activation of local AMPA-kainate and NMDA receptors in the NAc appears to underlie the changes in NAc DA efflux after BLA stimulation.

Given that brief $(10 \mathrm{sec})$ stimulation of the BLA is sufficient to induce changes in NAc DA efflux lasting for 20-30 min, mechanisms related to short-term potentiation may provide one possible explanation of these effects. Increased levels of intracellular $\mathrm{Ca}^{2+}$ resulting from NMDA receptor activation and increased $\mathrm{Ca}^{2+}$. dependent kinase activity have been implicated in synaptic plasticity (Bliss and Collingridge, 1993; Silva et al., 2000). Increased activity of kinases such as calcium-calmodulin-dependent kinase II and protein kinase A could increase DA efflux in the NAc by phosphorylating ionotropic receptors (Barria et al., 1997), proteins in the soluble $N$-ethylmaleimide-sensitive factor attached protein receptor complex (Risinger and Bennett, 1999), or altering the time course of slow afterhyperpolarizations (Muller et al., 1992; Silva et al., 2000). 


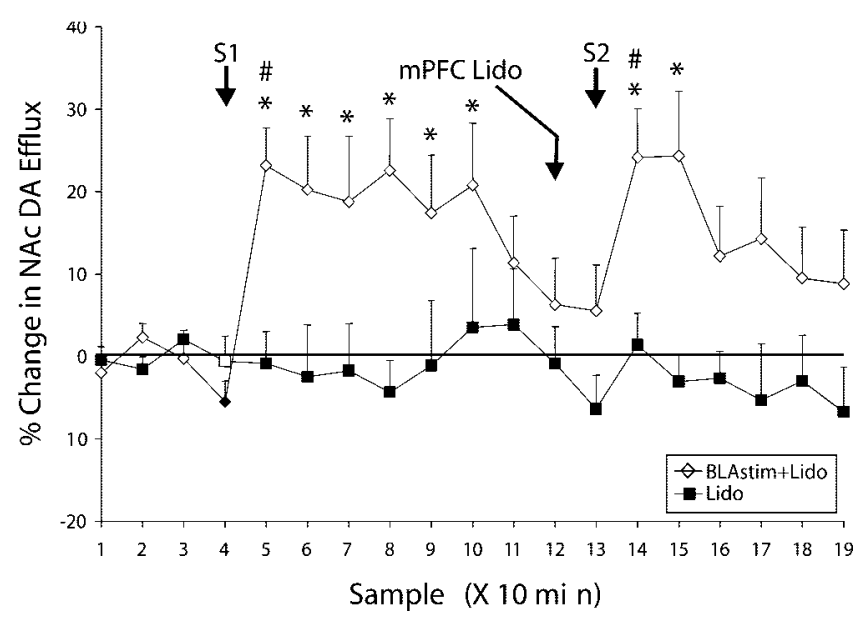

Figure 4. Effect of bilateral infusion of lido into the mPFC on BLA stimulation-evoked increases in NAc DA. Stimulation of the BLA $(20 \mathrm{~Hz}$, $10 \mathrm{sec}, S 1)$ induced a significant $23 \pm 5 \%$ increase in NAc DA efflux in the BLAstim + lido group (white diamonds; $n=9$ ). Lido infusion into the mPFC in both groups $(1 \mu \mathrm{l}$, bilateral, $m P F C$ lido $)$ failed to change basal DA levels significantly in either group (lido group, $n=9, p>0.05$ both groups). Stimulation was applied again to the BLAstim + lido group 10 min after the infusion $(20 \mathrm{~Hz}, 10 \mathrm{sec}, S 2)$, resulting in another significant $24 \pm 6 \%$ increase in NAc DA efflux. Asterisks denote a significant increase in DA levels above baseline (BLAstim + lido group, black diamond, $p<$ $0.05)$, and number signs indicate significant differences between groups $(p<0.001)$. Error bars represent SEM.

The central and medial nuclei of the amygdala have been described as the origin of the "extended amygdala," a continuum of neurons that extend into the bed nucleus of the stria terminalis, and through the basal forebrain to the NAc shell (Alheid and Heimer, 1988). Support for a functional role of the extended amygdala in learning and drug abuse has been described (Koob and Le Moal, 1997; Everitt et al., 1999); however, the anatomical complexity of this area makes experimental manipulation difficult. Although there are many anatomical connections within the continuum of neurons connecting the $\mathrm{CeN}$ to the NAc shell, the present data indicate that they may not be important in providing long-lasting regulation of NAc DA efflux. For example, it has also been proposed that the CeN could modulate NAc DA efflux via a GABAergic projection to the VTA, which may influence DA neurons (Everitt et al., 1999, 2000). Although efferents from the CeN do terminate in the VTA (Wallace et al., 1992; Fudge and Haber, 2000), evidence that these fibers synapse directly on mesoaccumbens DA neurons is lacking. Alternatively, the $\mathrm{CeN}$ may modulate DA cell firing in the VTA indirectly, via local circuit GABAergic interneurons (Wallace et al., 1992). The fact remains that brief stimulation of the $\mathrm{CeN}$ in the present study failed to evoke an increase in DA efflux, whereas a significant elevation in DA efflux was evoked by a similar level of activation in the BLA. However, given the 10 min sampling period used here, short acute changes in DA efflux cannot be ruled out.

Recent findings in our laboratory show that reverse dialysis of lido into the CeN significantly decreases basal DA levels in the NAc by $\sim 20 \%$ (Ahn and Phillips, 2001). Thus, GABAergic afferents from the $\mathrm{CeN}$ to the VTA may inhibit the extensive GABAergic interneuron network in the VTA under normal conditions. Inactivation of the $\mathrm{CeN}$ with lido would in turn increase the activity of inhibitory VTA GABAergic interneurons, thereby suppressing the firing of mesoaccumbens DA cells (Ahn and Phillips, 2001). According to this anatomical arrangement, brief stimulation of the GABAergic afferents from the $\mathrm{CeN}$ to the VTA could cause phasic inhibition of GABAergic interneurons and short-lasting increases in DA cell firing. Clearly, future experiments will be necessary to test these hypotheses.

\section{Evidence for local modulation of DA efflux in the NAc by the BLA}

Stimulation of the ventral subiculum of the hippocampus increases DA efflux in the NAc in both an impulse-dependent and impulse-independent manner (Blaha et al., 1997; Legault et al., 2000; Taepavarapruk and Phillips, 2001). Although the mechanisms by which the BLA can modulate NAc DA efflux are still poorly understood, data from the present experiments as well as Floresco et al. (1998), suggest that high-frequency stimulation of the BLA may regulate DA efflux in an impulse-independent manner. In the present study, only stimulation of the caudal BLA results in long-lasting increases in NAc DA efflux. As mentioned previously, this region of the BLA sends direct glutamatergic afferents to the NAc that overlap anatomically and functionally with mesoaccumbens DA afferents in the NAc. iGluRs are expressed in midbrain DA neurons (Sato et al., 1993; Standaert et al., 1994) and glutamatergic BLA afferents synapse in close apposition to tyrosine hydroxylase-containing varicosities on spines of individual medium spiny neurons (Johnson et al., 1994). Furthermore, NMDA receptors are located on tyrosine hydroxylase-containing varicosities in the NAc shell (Gracy and Pickel, 1996), thus providing a mechanism by which glutamate released from BLA afferents could modulate DA efflux presynaptically. Injections of glutamate or iGluR agonists into the NAc increases NAc DA efflux (Imperato et al., 1990; Desce et al., 1992; Ruzicka and Jhamandas, 1993; Youngren et al., 1993), whereas 6-OHDA lesions of the NAc reduce glutamate receptor binding in the NAc (French et al., 1985; Zavitsanou et al., 1996). Taken together, these findings support the hypothesis that iGluRs in the NAc may modulate DA efflux in an impulse-independent manner and are consistent with the finding that reverse dialysis of antagonists of iGluR into the NAc can block increases in DA efflux observed after BLA stimulation.

Two lines of evidence from the present study argue against an exclusive role for activation of cell firing in the VTA in BLA stimulation-evoked increases in DA efflux in the NAc. First, stimulation of the BLA remained effective at increasing NAc DA efflux even though DA cell body firing in the VTA was significantly suppressed by the infusion of $\mathrm{a} \mathrm{Na}^{+}$channel blocker (Fig. 3). A similar result was observed with an anesthetized preparation using chronoamperometry to monitor changes in DA oxidation current (Floresco et al., 1998). Second, inactivation of the mPFC also failed to block the increase in NAc DA efflux after BLA stimulation (Fig. 4). These two experiments provide support for our conjecture that regulation by the BLA of DA efflux in the NAc does not depend on activation of either DA cell bodies in the VTA or projection neurons from the mPFC to the VTA.

Although the caudal BLA does not project directly to the VTA, the BLA could still influence DA cell body firing through other indirect pathways including the direct glutamatergic afferent projection from the BLA to the mPFC (Jackson and Moghaddam, 2001). The mPFC is uniquely positioned to modulate DA efflux in the NAc as it projects to both the VTA and NAc (Kelley et al., 1982; Sesack et al., 1989), and evidence suggests that the mPFC may regulate DA efflux in the NAc through its glutamatergic afferents to the VTA (Taber and Fibiger, 1995; Karreman and Moghaddam, 1996). Additionally, others have 
shown that during activation of the BLA, changes in NAc DA efflux may be regulated by BLA afferents to the mPFC (Jackson and Moghaddam, 2001).

Jackson and Moghaddam (2001) reported that DA efflux in the NAc did not change significantly during a 10 min train of BLA stimulation, an effect these authors attributed to increased glutamate transmission in the mPFC. Despite the notable differences in the duration of electrical stimulation of the BLA in the study of Jackson and Moghaddam (2001) (10 min) as compared with the present experiments (10 sec), a significant increase in DA efflux in the NAc was observed in both studies after cessation of BLA stimulation. Interestingly, blockade of glutamate transmission in the mPFC did not affect the long-lasting increase in NAc DA efflux observed after prolonged stimulation of the BLA (Jackson and Moghaddam, 2001). When combined with the similar effect of lido inactivation of the mPFC in the present study, these data provide further support for our conclusion that stimulation of the BLA can modulate NAc DA efflux directly via local mechanisms within the NAc.

\section{Functional implications}

Everitt et al. (1999, 2000) emphasize that theories of amygdala function should account for different roles of amygdala nuclei in controlling adaptive behavioral responses. Specifically, they propose that interactions between the $\mathrm{CeN}$ and mesoaccumbens DA system in the VTA are necessary for reflexive Pavlovian conditioned responses, such as autoshaping (Parkinson et al., 2000a) and freezing behavior (Killcross et al., 1997). More flexible operant responses, demonstrated with conditioned reinforcement paradigms, appear to be subserved by interactions between the BLA and NAc (Everitt and Robbins, 1992; Killcross et al., 1997; Everitt et al., 1999; 2000; Parkinson et al., 2000a). The present data show that brief stimulation of the $\mathrm{CeN}$ comparable with firing rates elicited by rewarding stimuli (Muramoto et al., 1993; Uwano et al., 1995) does not affect DA efflux in the NAc when integrated over a 10 min period. However, the possibility still remains that activation of the $\mathrm{CeN}$ can elicit short-lasting changes in mesoaccumbens DA efflux. In contrast, stimulation of the BLA induces a long-lasting increase in DA efflux in the NAc. Additional data from our laboratory suggest that the BLA can autoregulate its afferent input to the NAc as a consequence of evoked increases in DA efflux (Floresco et al., 2001a). In summary, the interaction of the CeN with the DA cell bodies in the VTA may cause the animal to engage in a more restrictive, reflexive response to salient stimuli, whereas local changes in DA efflux in the NAc produced by high-frequency stimulation of the BLA may facilitate "behavioral switching" in complex, constantly changing environments (Floresco et al., 2001a,b).

\section{REFERENCES}

Ahn S, Phillips AG (1999) Dopaminergic correlates of sensory-specific satiety in the medial prefrontal cortex and nucleus accumbens of the rat. J Neurosci 19:RC29.

Ahn S, Phillips AG (2001) Differential effects of transient inactivations of the basolateral and central amygdala on basal and food-evoked dopamine efflux in the rat nucleus accumbens. In: Monitoring molecules in neuroscience, Proceedings of the $9^{\text {th }}$ International Conference on In Vivo Methods (O'Connor WT, Lowry JP, O'Connor JJ, and O'Neill RD, eds), pp 111-112. Dublin: University College Dublin.

Alheid GF, Heimer L (1988) New perspectives in basal forebrain organization of special relevance for neuropsychiatric disorders: the striatopallidal, amygaloid, and corticopetal components of the substantia innominata. Neuroscience 27:1-39.

Baldwin AE, Holahan MR, Sadeghia K, Kelley AE (2000) $N$-methyl-Daspartate receptor-dependent plasticity within a distributed corticostriatal network mediates appetitive instrumental learning Behav Neurosci 114:84-98.
Barria A, Muller D, Derkach V, Griffith LC, Soderling TR (1997) Regulatory phosphorylation of AMPA-type glutamate receptors by CaMK-II during long-term potentiation. Science 276:2042-2045.

Björklund A, Lindvall O (1984) Dopamine-containing systems in the CNS. In: Handbook of chemical neuroanatomy: classical transmitters in the rat, Vol 2 (Björkland A and Hokfelt T, eds), pp 55-122. Amsterdam: Elsevier/North Holland.

Blaha CD, Yang CR, Floresco SB, Barr A, Phillips AG (1997) Stimulation of the ventral subiculum of the hippocampus evokes glutamate receptor mediated changes in dopamine efflux in the rat nucleus accumbens. Eur J Neurosci 9:902-911.

Bliss TVP, Collingridge GL (1993) A synaptic model of memory: longterm potentiation in the hippocampus. Nature 361:31-39.

Brog JS, Salyapongse A, Deutch AY, Zahm DS (1993) The pattern of afferent innervation of the core and shell in the "accumbens" part of the ventral striatum: immunohistochemical detection of retrogradely transported fluoro-gold. J Comp Neurol 338:255-278.

Cador M, Robbins TW, Everitt BJ (1989) Involvement of the amygdala in stimulus-reward associations: interactions with the ventral striatum. Neuroscience 30:77-86.

Davis M (1992) The role of the amygdala in conditioned fear. In: The amygdala: neurobiological aspects of emotions, memory and mental dysfunctions (Aggleton JP, ed), pp 255-306. New York: Wiley-Liss.

Desce JM, Godeheu G, Galli T, Artaud F, Cheramy A, Glowinski J (1992) 1-glutamate-evoked release of dopamine from synaptosomes of the rat striatum: involvement of AMPA and $N$-methyl-D-aspartate receptors. Neuroscience 47:333-339.

Everitt BJ, Morris KA, O'Brien A, Burns L, Robbins TW (1991) The basolateral amygdala-ventral striatal system and conditioned place preference: further evidence of limbic-striatal interactions underlying reward-related processes. Neuroscience 41:1-18.

Everitt BJ, Parkinson JA, Olmstead MC, Arroyo M, Robledo P, Robbins TW (1999) Associative processes in addition and reward: the role of amygdala-ventral striatal subsystems. Ann NY Acad Sci 877:412-438.

Everitt BJ, Cardinal RN, Hall J, Parkinson JA, Robbins TW (2000) Differential involvement of amygdala subsystems in appetitive conditioning and drug addiction. In: The amygdala: Ed 2, A functional analysis (Aggleton JP, ed), pp 353-390. New York: Oxford UP.

Floresco SB, Yang CR, Phillips AG, Blaha CD (1998) Basolateral amygdala stimulation evokes glutamate receptor-dependent dopamine efflux in the nucleus accumbens of the anaesthetised rat. Eur J Neurosci 10:1241-1251.

Floresco SB, Blaha CD, Yang CR, Phillips AG (2001a) Modulation of hippocampal and amygdalar-evoked activity of nucleus accumbens neurons by dopamine: cellular mechanisms of input selection. J Neurosci 21:2851-2860.

Floresco SB, Blaha CD, Yang CR, Phillips AG (2001b) Dopamine D1, NMDA receptors mediate potentiation of basolateral amygdala-evoked firing of nucleus accumbens neurons. J Neurosci 21:6370-6376.

French ED, Pilapil C, Quirion R (1985) Phencyclidine binding sites in the nucleus accumbens and phencyclidine-induced hyperactivity are decreased following lesions of the mesolimbic dopamine system. Eur J Pharmacol 116:1-9.

Fudge JL, Haber SN (2000) The central nucleus of the amygdala projection to dopamine subpopulations in primates. Neuroscience 97:479-494.

Gracy KN, Pickel VM (1996) Ultrastructural immunocytochemical localization of the $N$-methyl-D-aspartate receptor and tyrosine hydroxylase in the shell of the rat nucleus accumbens. Brain Res 739:169-181.

Groenewegen HJ, Berendse HW, Meredith GE, Haber SN, Voorn P, Wolters JG, Lohman AHM (1991) Functional anatomy of the ventral, limbic system-innervated striatum. In: The mesolimbic dopamine system (Willner P, Scheel-Kruger J, eds), pp 19-59. New York: Wiley.

Harvey J, Lacey MG (1997) A postsynaptic interaction between dopamine $\mathrm{D}_{1}$ and NMDA receptors promotes presynaptic inhibition in the rat nucleus accumbens via adenosine release. J Neurosci 17:5271-5280.

Hatfield T, Han JS, Conley M, Gallagher M, Holland P (1996) Neurotoxic lesions of basolateral, but not central, amygdala interfere with Pavlovian second-order conditioning and reinforcer devaluation effects. J Neurosci 16:5256-5265.

Hernándéz-López S, Baragas J, Surmeier DJ, Reyes A, Galarraga E (1997) $D_{1}$ receptor activation enhances evoked discharge in neostriatal medium spiny neurons by modulating an L-type $\mathrm{Ca}^{2+}$ conductance. J Neurosci 17:3334-3342.

Ikemoto S, Panksepp J (1999) The role of nucleus accumbens dopamine in motivated behavior: a unifying interpretation with special reference to reward seeking. Brain Res Rev 31:6-41.

Imperato A, Scrocco MG, Bacchi S, Angelucci L (1990) NMDA receptors and in vivo dopamine release in the nucleus accumbens and caudatus. Eur J Pharmacol 187:555-556.

Jackson ME, Moghaddam B (2001) Amygdala regulation of nucleus accumbens dopamine output is governed by the prefrontal cortex. J Neurosci 21:676-681.

Johnson LR, Aylward RLM, Hussain Z, Totterdell S (1994) Input from the amygdala to the rat nucleus accumbens: its relationship with ty- 
rosine hydroxylase immunoreactivity and identified neurons. Neuroscience 61:851-865.

Karreman M, Moghaddam B (1996) The prefrontal cortex regulates the basal release of dopamine in the limbic striatum: an effect mediated by ventral tegmental area. J Neurochem 66:589-598.

Kelley AE, Domesick VB, Nauta JH (1982) The amygdalo-striatial projection in the rat-an anatomical study by anterograde and retrograde tracing methods. Neuroscience 7:615-630.

Killcross S, Robbins TW, Everitt BJ (1997) Different types of fearconditioned behavior mediated by separate nuclei within amygdala. Nature 388:377-380.

Koob GF, Le Moal M (1997) Drug abuse: hedonic homeostatic dysregulation. Science 278:52-58

Kretteck JE, Price JL (1978) A description of the amygdaloid complex in the rat and cat with observations on intra-amygdaloid axonal connections. J Comp Neurol 178:255-280.

Legault M, Rompré P-P, Wise RA (2000) Chemical stimulation of the ventral hippocampus elevates nucleus accumbens dopamine by activating dopaminergic neurons of the ventral tegmental area. J Neurosci 20:1635-1642.

Meredith GE, Totterdell S (1999) Microcircuits in nucleus accumbens' shell and core involved in cognition and reward. Psychobiology 27:165-186.

Mogenson GJ, Brudzynski SM, Wu M, Yang CR, Yim CY (1993) From motivation to action: a review of dopaminergic regulation of limbic/ nucleus accumbens/ventral pallidum/pedunculopontine nucleus circuitries involved with limbic-motor integration. In: Limbic motor circuits and neuropsychiatry (Kalivas PW, Barnes CD, eds), pp 193-263. Boca Raton, FL: CRC.

Muller W, Petrozzino JJ, Griffith LC, Danho W, Connor JA (1992) Specific involvement of $\mathrm{Ca}(2+)$-calmodulin kinase II in cholinergic modulation of neuronal responsiveness. J Neurophysiol 68:2264-2269.

Muramoto K, Ono T, Nishijo H, Fukuda M (1993) Rat amygdaloid neuron responses during auditory discrimination. Neuroscience 52:621-636.

Nicola SM, Surmeier DJ, Malenka RC (2000) Dopaminergic modulation of neuronal excitability in the striatum and nucleus accumbens. Annu Rev Neurosci 23:185-215.

Parkinson JA, Olmstead MC, Burns LH, Robbins TW, Everitt BJ (2000a) Dissociation in effects of lesions of the nucleus accumbens core and shell on appetitive Pavlovian approach behavior and the potentiation of conditioned reinforcement and locomotor activity by D-amphetamine. J Neurosci 19:2401-2411.

Parkinson JA, Robbins TW, Everitt BJ (2000b) Dissociable roles of the central and basolateral amygdala in appetitive emotional learning. Eur J Neurosci 12:405-413.

Paxinos G, Watson C (1997) The rat brain in stereotaxic co-ordinates, Ed 3. San Diego: Academic.

Pratt WE, Mizumori SJY (1998) Characteristics of basolateral amygdala neuronal firing on a spatial memory task involving differential reward. Behav Neurosci 112:554-570.

Redgrave P, Prescott TJ, Gurney K (1999) Is the short-latency dopamine response too short to signal reward error? Trends Neurosci 22:146-151.

Risinger C, Bennett MK (1999) Differential phosphorylation of syntaxin and syaptosome-associated protein of $25 \mathrm{kDa}$ (SNAP-25) isoforms. J Neurochem 72:614-624.

Robbins TW, Everitt BJ (1992) Amygdala-ventral striatal interactions and reward related processes. In: The amygdala: neurobiological aspects of emotions, memory and mental dysfunctions (Aggleton JP, ed), pp 401-429. New York: Wiley-Liss.

Robledo P, Robbins TW, Everitt BJ (1996) Effects of excitotoxic lesions of the central amygdaloid nucleus on the potentiation of reward-related stimuli by intra-accumbens amphetamine. Behav Neurosci 110:981-990.
Ruzicka BB, Jhamandas KH (1993) Excitatory amino acid action on the release of brain neurotransmitters and neuromodulators: biochemical studies. Prog Neurobiol 40:223-247.

Sato K, Kiyama H, Tohyama M (1993) The differential expression patterns of messenger RNAs encoding non- $N$-methyl-D-aspartate glutamate receptor subunits (GluR1-4) in the rat brain. Neuroscience 52:515-539.

Sesack SR, Deutch AY, Roth RH, Bunney BS (1989) Topographical organization of the efferent projections of the medial prefrontal cortex in the rat: an anterograde tract-tracing study with Phaseolus vulgaris leucoagglutinin. J Comp Neurol 290:213-242.

Silva AJ, Elgersma Y, Costa RM (2000) Molecular and cellular mechanisms of cognitive function: implications for psychiatric disorders. Biol Psychiatry 47:200-209.

Standaert DG, Testa CM, Young AB, Penny JB Jr (1994) Organization of $N$-methyl-D-aspartate glutamate receptor gene expression in the basal ganglia of the rat. J Comp Neurol 343:1-16.

Swanson LW, Petrovich GD (1998) What is the amygdala? Trends Neurosci 21:323-331.

Taber MT, Fibiger HC (1995) Electrical stimulation of the prefrontal cortex increases dopamine release in the nucleus accumbens of the rat: modulation by metabotropic glutamate receptors. J Neurosci 15:3896-3904.

Taepavarapruk P, Phillips AG (2001) Role of the prefrontal cortex and the ventral tegmental area in mediating release of dopamine in the nucleus accumbens evoked by stimulation of the ventral subiculum. In: Monitoring molecules in neuroscience, Proceedings of the $9^{\text {th }}$ International Conference on In Vivo Methods (O'Connor WT, Lowry JP, O'Connor JJ, and O'Neill RD, eds), pp 223-224. Dublin: University College Dublin.

Taepavarapruk P, Floresco SB, Phillips AG (2000) Hyperlocomotion and increased dopamine efflux in the nucleus accumbens evoked by electrical stimulation of the ventral subiculum: role of ionotropic glutamate and dopamine $\mathrm{D}_{1}$ receptors. Psychopharmacology 151:242-251.

Taylor JR, Robbins TW (1986) 6-hydroxydopamine lesions of the nucleus accumbens, but not of the caudate nucleus, attenuate enhanced responding with reward-related stimuli produced by intra-accumbens D-amphetamine. Psychopharmacology 90:390-397.

Tehovnik EJ, Sommer MA (1997) Effective spread and time course of neural inactivation caused by lidocaine injection in monkey cerebral cortex. J Neurosci Methods 74:17-26.

Uwano T, Nishijo H, Ono T, Tamura R (1995) Neuronal responsiveness to various sensory stimuli, and associative learning in the rat amygdala. Neuroscience 68:339-361.

Wallace DM, Magnuson DJ, Gray TS (1992) Organization of amygdaloid projections to brainstem dopaminergic, noradrenergic and adrenergic cell groups in the rat. Brain Res Bull 28:447-454.

Wickens JR, Begg AJ, Arbuthnott GW (1996) Dopamine reverses the depression of rat corticostriatal synapses which normally follows highfrequency stimulation of the cortex in vitro. Neuroscience 70:1-5.

Wright CI, Beijer AVJ, Groenewegen HJ (1996) Basal amygdaloid complex afferents to the rat nucleus accumbens are compartmentally organized. J Neurosci 16:1877-1893.

Youngren KD, Daly DA, Moghaddam B (1993) Distinct actions of endogenous excitatory amino acids on the outflow of dopamine in the nucleus accumbens. J Pharmacol Exp Ther 264:289-293.

Zahm DS (2000) An integrative neuroanatomical perspective on some subcortical substrates of adaptive responding with emphasis on the nucleus accumbens. Neurosci Biobehav Rev 24:85-105.

Zavitsanou K, Mitsacos A, Giopres P, Kouvelas ED (1996) Changes in $[3 \mathrm{H}] \mathrm{AMPA}$ and $[3 \mathrm{H}] \mathrm{kainate}$ binding in rat caudate-putamen and nucleus accumbens after 6-hydroxydopamine lesions of the medial forebrain bundle: an autoradiographic study. Brain Res 731:132-140. 